EESTI NSV TEADUSTE AKADEEMIA TOIMETISED. XVII KOIDE

KEEMIA * GEOLOOGIA. 1968, Nr. 2

ИЗВЕСТИЯ АКАДЕМИИ НАУК ЭСТОНСКОИ ССР. ТОМ ХVII

ХИМИЯ * ГЕОЛОГИя. 1968, №2 2

5. МЯННИК, А. ФОМННА, Ю. КАНН, О. ИКОНОПИСЦЕВА

\title{
АНАЛИЗ СМЕСЕЙ ДИКАРБОНОВЫХ КИСЛОТ, ПОЛУЧЕННЫХ ОКИСЛЕНИЕМ КЕРОГЕНА КУКЕРСИТА, МЕТОДОМ ГАЗО- ЖИДКОСТНОЙ ХРОМАТОГРАФИИ
}

O перспективном методе получения дикарбоновых кислот $\mathrm{C}_{4}-\mathrm{C}_{10}$, заключающемся в окислении горючего сланца кукерсита, сообщалось уже раньше $\left[{ }^{1-3}\right]$. Смеси полученных таким способом кислот содержат в качестве примесей и другие продукты окисления неустановленного состава. Кроме того, компонентный состав смесей меняется в широких пределах в зависимости от режима окисления, способа очистки (дистилляция, перекристаллизация) и т. д. Поэтому анализ конечных продуктов представляется довольно сложной задачей.

Вопрос анализа указанных смесей в известной степени был разрешен применением распределительной хроматографии [ [4].

В настоящей работе впервые рассматривается возможность использования газожидкостной хроматографии для анализа смесей очищенных дикарбоновых кислот, полученных окислением керогена кукерсита комбинированным окислителем - азотной кислотой и воздухом.

В литературе имеется достаточное число работ, посвященных газохроматографическому анализу различных сочетаний дикарбоновых кислот. Подробный перечень этих работ приводится в монографии Г. Берчфилда и Э. Сторрс [6], а также в сообщениях [5] и [7]. Однако авторы этих работ не указывают соотношений определяемых компонентов в смесях, хотя их очень важно знать при выборе условий количественного анализа, и совершенно не приводят цифровых данных.

Поскольку дикарбоновые кислоты сравнительно мало устойчивы при повышенных температурах и склонны к образованию водородных связей, признано целесообразным хроматографировать их в виде диметиловых эфиров [5]. Разделение диметиловых эфиров дикарбоновых кислот проводят либо на неполярных жидких стационарных фазах (силиконовые жидкости: $E=301, S E=30$ и вакуумные смазки: апиезон $M$, апиезон $L$ и др.), либо на полярных жидкостях типа полиэфиров двухатомных спиртов и дикарбоновых кислот, отличающихся числом углеродных атомов в исходных мономерах $\left[{ }^{6-8}\right]$. В качестве твердых носителей используют хромосорб $\mathbb{W}$, целит 545 и некоторые другие марки огнеупорного кирпича.

При анализе полярных соединений, какими являются диметиловые эфиры дикарбоновых кислот, особенно сильно прсявляется остаточная адсорбционная активность твердого носителя (образование «хвостоз» у пиков). Поэтому в процессе работы возникла необходимость в оценке 
нового твердого носителя, разработанного И. Мусаевым с соавторами на основе отечественного носителя ИНЗ-600 [ $\left.{ }^{8}\right]$.

Размер зерен твердого носителя - 0,43-0,65 мм. В качестве жидкой стационарной фазы использовался полиэтиленгликольглутарат (мол. вес 570), синтезированный по методике [9]; концентрация жидкой неподвижной фазы составляла $7 \%$ по отношению к твердому носителю. Оптимальная длина колонки, установленная в опытах с модельными смесями эфиров чистых кислот, достигала $2 \mu$; внутренний диаметр еє - 6 мм. Давление газа-носителя (гелия) на входе в колонку было на $0,25 \kappa \Gamma c / c M^{2}$ выше атмосферного, на выходе - атмосферное; скорость потока газа-носителя, измеренная пузырьковым счетчиком, 120 мл/мин. Анализ проводился при температуре колонки $180^{\circ}$, на хроматографе GCHF-18 (фирма Willi Giede). Детектор хроматографа представляет собой двухканальный катарометр с платиновыми нитями в качестве элементов сопротивления. Продолжительность анализа до выхода эфира себациновой кислоты - 20 мин.

Навеску дистиллята кислот в 0,2 г растворяли в диэтиловом эфире и метилировали диазометаном в эфирном растворе до прекращения выделения азота; растворитель практически полностью удаляли выпариванием, и 5-10 мл полученного раствора микрошприцем вводили в нспаритель хроматографа. Типичная хроматограмма дистиллята кислот приведена на рис. 1.

Расчет анализа проводился методом внутренней нормировки по диметиловому эфиру адипиновой кислоты [6]. На основании анализа спе-

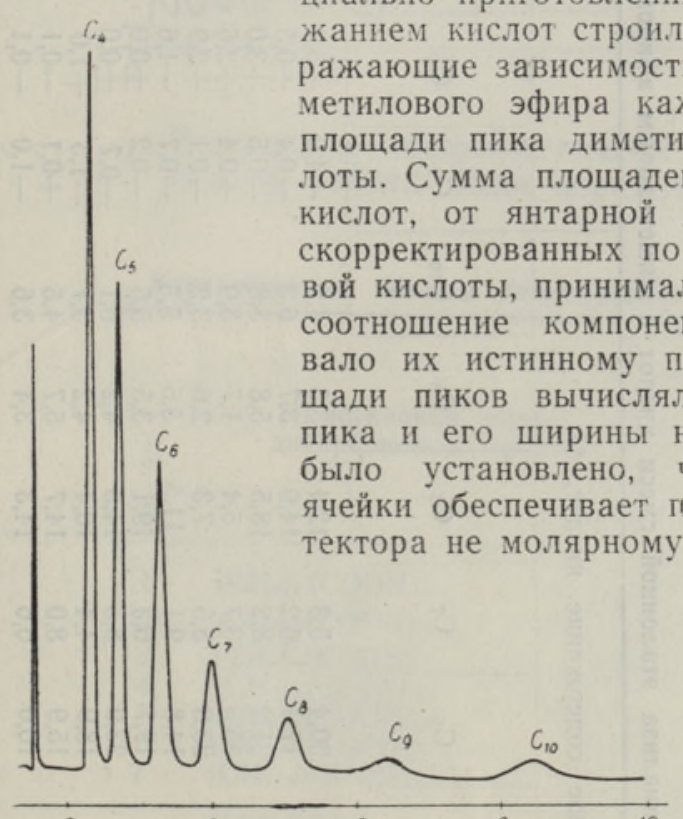

Рнс. 1. Хроматограмма диметиловых эфиров дистиллята сланщевых дикарбоновых кислот.

[6], а весовому, что существенно упрощает расчет. Результаты контрольных анализов приведены в табл. 1 .

Как видно из данных табл. 1, абсолютная ошибка определения не превышает $\pm 3,5 \%$. Примененные твердый носитель и жидкая фаза в данных условиях могут обеспечить надежную работу колонки в течение более чем 1200 часов. К концу этого периода на хроматограммах тыл 


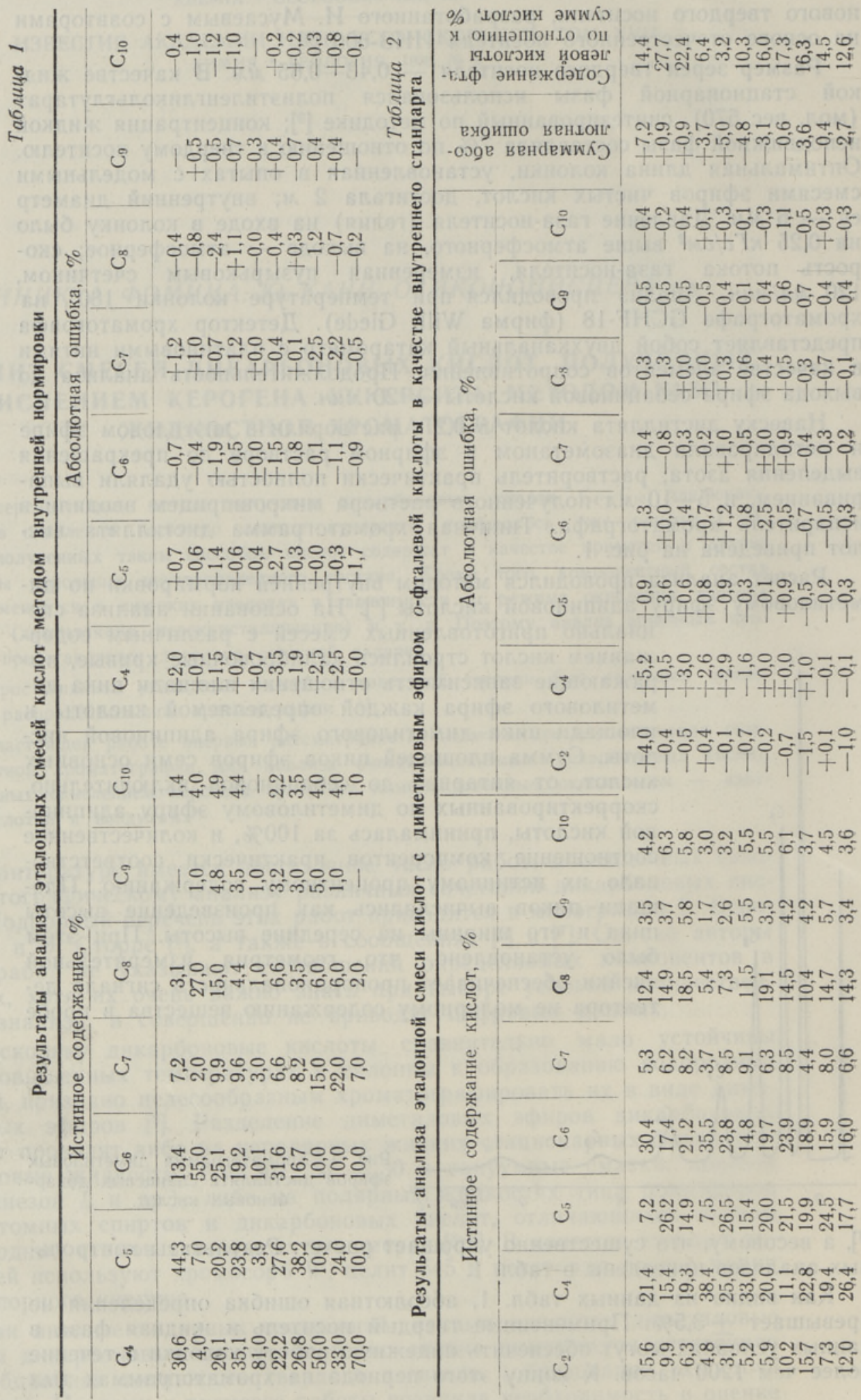




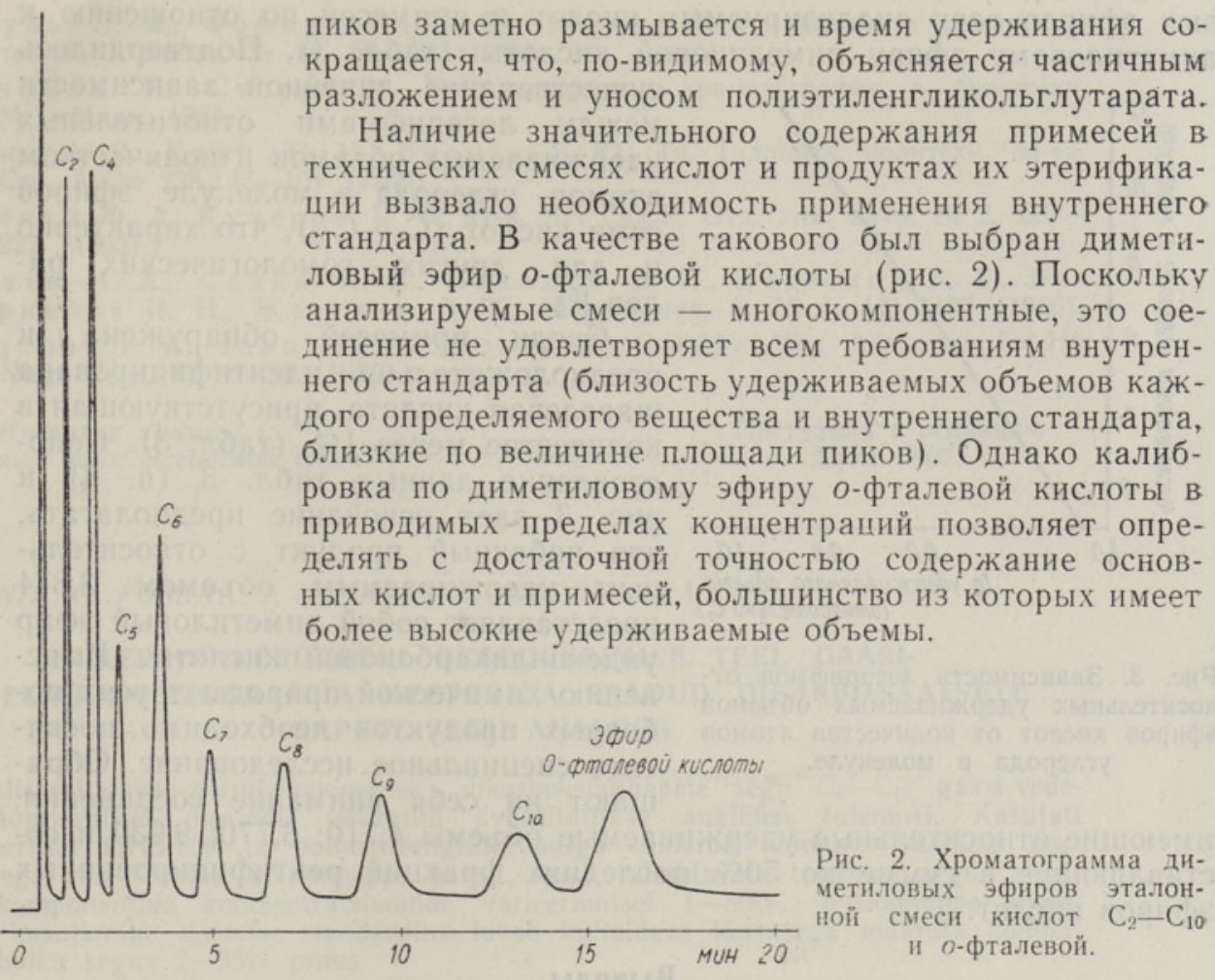

Результаты анализов смесей чистых кислот приводятся в табл. 2. В ходе работы были определены удерживаемые объемы диметило-

Таблица 3

Удерживаемые объемы диметиловых эфиров дикарбоновых кислот и примесей

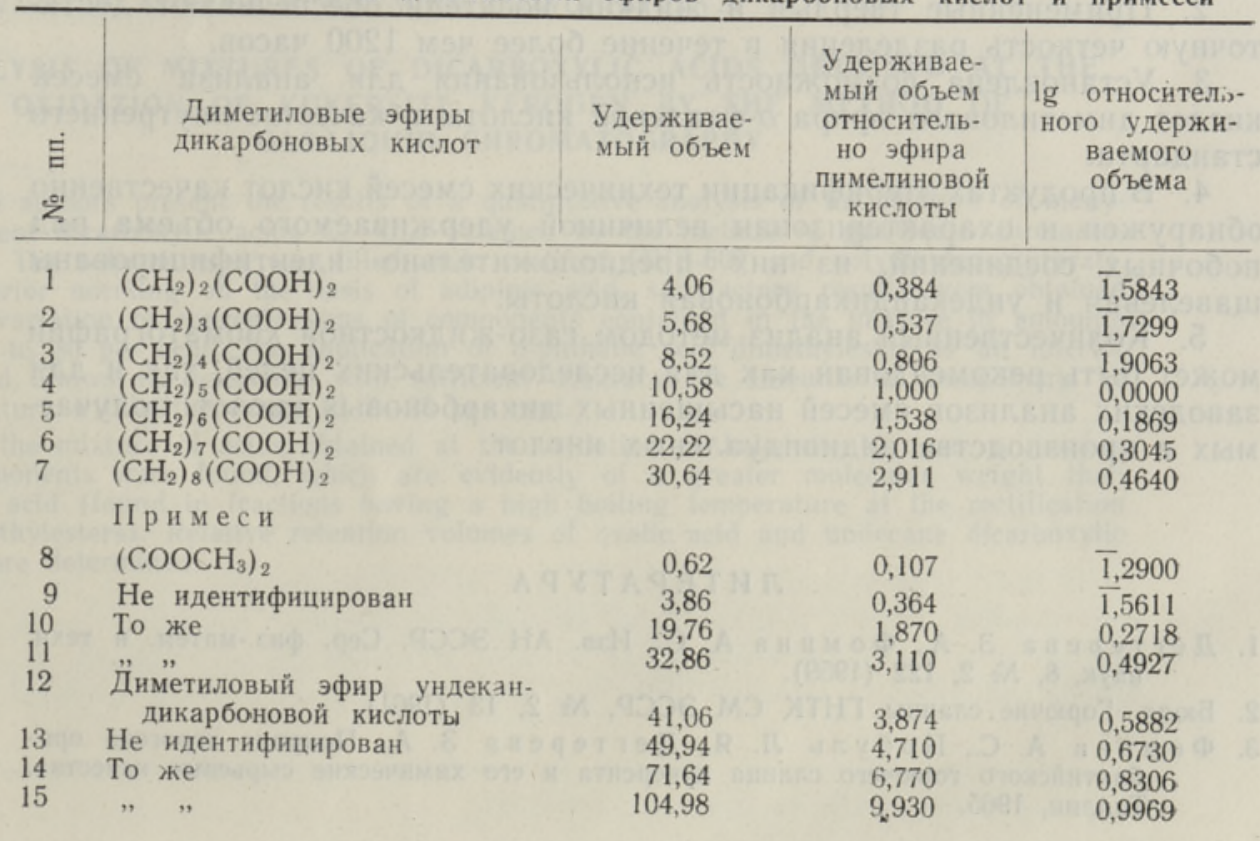


вых эфиров всех анализируемых кислот и примесей по отношению к диметиловому эфиру пимелиновой кислоты (табл. 3). Подтвердилось

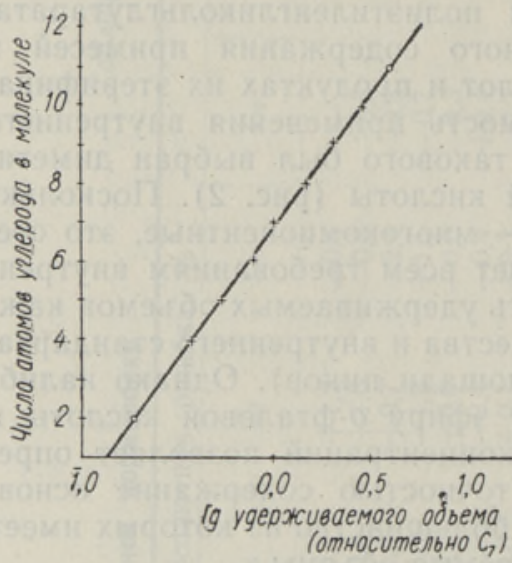

Рис. 3. Зависимость логарифмов огносительных удерживаемых объемов эфиров кислот от количества атомов углерода в молекуле.

существование линейной зависимости между логарифмами относительных удерживаемых объемов и количеством атомов углерода в молекуле эфиров семи кислот $\left(\mathrm{C}_{4}-\mathrm{C}_{10}\right)$, что характерно и для других гомологических рядов [5].

Среди примесей обнаружена и предположительно идентифицирована щавелевая кислота, присутствующая в количестве менее $1 \%$ (табл. 3). Сопоставление данных табл. 3 (п. 8) и рис. 3 дает основание предполагать, что побочный продукт с относительным удерживаемым объемом 3,874 представляет собой диметиловый эфир ундекандикарбоновой кислоты. Выяснению химической природы других побочных продуктов необходимо посвятить специальное исследование. Обрашают на себя внимание соединения, имеющие относительные удерживаемые объемы 4,$710 ; 6,770 ; 9,930$ и составляющие в сумме до $50 \%$ последних фракций ректифицированных эфиров кислот.

\section{Выводы}

1. Разработана методика газохроматографического анализа сравнительно сложной смеси кислот, получаемых окислением керогена кукерсита, в виде их диметиловых эфиров на стационарных фазах: модифицированный ИНЗ-600 и полиэтиленгликольглутарат.

2. Примененные твердый и жидкий носители обеспечивают достаточную четкость разделения в течение более чем 1200 часов.

3. Установлена возможность использования для анализа смесей кислот диметилового эфира о-фталевой кислоты в качестве внутреннего стандарта.

4. В продуктах этерификации технических смесей кислот качественно обнаружен и охарактеризован величиной удерживаемого объема ряд побочных соединений, из них предположительно идентифицированы щавелевая и ундекандикарбоновая кислоты.

5. Количественный анализ методом газо-жидкостной хроматографии может быть рекомендован как для исследовательских целей, так и для заводских анализов смесей насыщенных дикарбоновых кислот, получаемых в производстве индивидуальных кислот.

\section{ЛИТЕРА Т У Р А}

1. Дегтерева 3. А., Фомина А. С., Изв. АН ЭССР. Сер. физ.-матем. и техн. наук, 8, № 2, 122 (1959).

2. Бюлл. Горючие сланцы ГНТК СМ ЭССР, № 2, 13 (1961).

3. Фомина А. С., Побуль Л. Я., Дегтерева 3. А., Природа керогена прибалтийского горючего сланца кукерсита и его химические сырьевые каче́ства. Таллин, 1965. 
4. Побуль Л. Я., Фомина А. С., Дегтерева 3. А., Химпя и технология топлив и масел, № 10, 55-59 (1961).

5. Берчфилд Г., Сторрс Э.. Газо-жидкостная хроматография в биохимии. М., «Мир», 1964.

6. Аарна А. Я., Канн Ю. М., Виркус А. Ю., Тр. Таллинск. политехн. ин-та. Cep. A, № 238, 93-101 (1966).

7. Руденко Ф. А., Кучеров В. Ф., Изв. АН СССР. Отд. хим. наук, № 2, $220-$ 227 (1963).

8. Мусаев И. А., Санин П. И., Пахомов В. П., Березкин В. Г., Ба ринов а Н. Н., Жестков Д. К., Нефтехимия, 6, № 1, 131-137 (1966).

9. Farquhar I. W., Insull J. W. Rosen P., Steffel W., Ahrens E. H., Nutr. Revs, 17, $1-30$ (1959).

Ннститут химии

Академии наук Эстонской ССР
Поступила в редакцию 20/XI 1967

\section{E. MANNIK, A. FOMINA, J. KANN, O. IKONOPISTSEVA}

\section{KUKERSIIDIKEROGEENI OKSUDEERIMISE TEEL GAASI- VEDELIKKROMATOGRAAFIA MEETODIGA SAADUD DIKARBONAATSETE HAPETE SEGU ANALUUS}

Artiklis esitatakse paljukomponentse dikarboksüülhapete segu $\mathrm{C}_{4}-\mathrm{C}_{10}$ gaasi-vedelikkromatograafilisel meetodil teostatud kvantitatiivse analüüsi tulemusi. Kasutati modifitseeritud ИН3-600 ja polüetüleenglutaraadiga täidetud kolonni. Sisemise normeerimisega, mis teostati adipiinhappe baasil, saadi rahuldavaid tulemusi segus sisalduvate komponentide kontsentratsioonide varieerumisel $1-80 \%$. $o$-ftalhappe dimetüülestri kasutamine sisemise standardina lubab küllaldase täpsusega määrata komponentide hulka segus $2-35 \%$ piires.

Põlevkivikerogeeni oksüdeerimisel saadud hapete segus leiti terve rida komponente, mis on nähtavasti suurema molekulkaaluga kui sebatsiinhape (leitud dimetüülestrite rektifitseerimisel saadud kõrge keemistemperatuuriga fraktsioonidest). Suhteliste väljumismahtudega määrati oblik-ja undekaandikarboksüülhape.

\section{E. MANNIK, A. FOMINA, J. KANN, O. IKONOPISTSEVA}

\section{ANALYSIS OF MIXTURES OF DICARBOXYLIC ACIDS OBTAINED AT THE OXIDATION OF KUKERSITE KEROGEN BY THE METHOD OF GAS-LIQUID CHROMATOGRAPHY}

The authors present the results of a quantitative analysis of the mixture of manycomponent dicarboxylic acids $\mathrm{C}_{4}-\mathrm{C}_{10}$, obtained by the method of gas-liquid chromatography. The column used was filled with modified ИН3-600 and polyethyleneglutarate. By interior norming on the basis of adipinic acid, satisfactory results were obtained at the variation of concentrations of components contained in the mixture in amounts from 1 to 80 per cent. The application of $o$-phthalic acid dimethylester as an interior standard allows to determine with sufficient accuracy the amounts of components in the mixture within the range of $2-35$ per cent.

In the mixture of acids obtained at the oxidation of kukersite kerogen, a number of components were found, which are evidently of a greater molecular weight than sebacic acid (found in fractions having a high boiling temperature at the rectification of dimethylesters). Relative retention volumes of oxalic acid and undecane dicarboxylic acid were determined. 